\title{
A Practical Method to Account for Seal Friction in Aircraft Hydraulic Actuator Preliminary Design
}

\author{
Naresh Kumar Agarwal \\ Aerospace Systems \& Equipment R \& D \\ Centre \\ Hindustan Aeronautics Limited, \\ Lucknow - India \\ naresh_hal@rediffmail.com
}

\author{
Craig P. Lawson \\ School of Aerospace, Transport and \\ Manufacturing, \\ Cranfield University, \\ UK \\ c.p.lawson@cranfield.ac.uk
}

\begin{abstract}
Seals are used in hydraulic actuators or any other hydraulic devices to prevent passing of hydraulic fluid from one chamber to another, or to prevent external leakage and entry of any foreign contaminants. The primary function of any hydraulic actuator is to efficiently use hydraulic power to drive a load experienced during movement of control surfaces or movable aircraft structure. Efficient sealing helps in achieving this, but with its own friction which should be as minimal as possible. Thus, the estimation of seal friction force has crucial significance in hydraulic actuators, especially in flight control actuators which demand high performance and dynamic behavior characteristics while efficiently driving the load. This paper details the methodology adopted for theoretical estimation of total seal friction force of actuator as well as description of experimental test set-up and test method followed to record the total friction value at different positions of the actuator. The theoretical estimation was done using empirical formulae and graphs for predicting seal friction force by considering the effects of seal squeeze, hydraulic pressure, seal dimensions, seal material and then interpolating the same for the specific type of seals used. An experimental study is also presented in this paper which can be conducted to validate the theoretically estimated value after building up of development prototypes. The validation is necessary as seal friction force calculation during design phase is an approximation and accurate friction of every seal is difficult to measure as it depends on a number of parameters. Thus, this paper explains the subject issue with the help of a case study which provides the theoretical estimation as well as its validation through an experiment to study this significant aspect of a hydraulic actuator design.
\end{abstract}

\section{KEYWORDS}

Actuator Effort, Ener Cap, Friction, Hydraulic Pressure, Hydraulic Seal, Stall Load

$\begin{array}{ll}A & \text { Seal projected area } \\ D_{c} & \text { Cylinder internal diameter } \\ D_{g} & \text { Gland internal diameter } \\ d_{g p} & \text { Piston groove outer diameter } \\ D_{g r} & \text { Gland groove internal diameter } \\ d_{p} & \text { Piston outer diameter } \\ d_{r} & \text { Piston rod outer diameter } \\ F & \text { Friction force } \\ F_{C} & \text { Total friction force due to seal squeeze } \\ f_{c} & \text { Friction per seal contact length } \\ \mathrm{F}_{H} & \text { Total friction force due to fluid pressure } \\ f_{h} & \text { Friction per seal projected area } \\ L & \text { Circumference }\end{array}$

\section{NOMENCLATURE}

\section{INTRODUCTION}

Hydraulic seals are used to keep fluids from escaping from cylinders or any other hydraulic device and to prevent entry of any foreign contaminants. These seals; help to create a method for fluid power to be converted into linear motion utilizing pressurized hydraulic fluid, and are absolutely vital especially for flight control actuators. However, these functional objectives alone are not sufficient for servo actuators where positioning accuracy with dynamic behavior is of great importance, and here seal friction behavior is of crucial significance. The life and efficiency of hydraulic 
actuators and thus complete hydraulic systems are dependent to a great extent on seals friction. Wear and tear are associated with this friction phenomenon. Hence, it is necessary to consider the effect of seal friction in the design of actuators from the preliminary design phase itself; to avoid any non performance at a later date which may result in project delay and cost overrun. The piston effective area needs to be calculated again after consideration of seals friction as the actuator must be able to overcome this friction to initiate its movement and also to drive the stall load expected on the actuator. Reduced seal friction also improves wear and tear characteristics of seals which results in actuator enhanced life and efficiency.

Conventionally, either the designer just ignores to include the effect of seal friction during the preliminary design phase, or considers the value as provided by seals supplier. It is also noticed a number of times that seals suppliers provide the seal friction value towards significantly higher side; sometimes up-to 60 to $70 \%$ higher than the actual value as obtained through testing. This is because, the friction value estimation is usually done by them for the worst case scenarios, with the assumption of low lubrication/poor surface finish of components and many others. Ultimately, this results in overdesign by selecting higher cylinder annular area. However, the seal supplier always advises that the true seal friction values can be obtained through testing by the user only, as there are so many variables in sealing.

"Stall load" is an important design parameter and thus needs to be considered from the preliminary design phase itself for any hydraulic actuator. Stall load is the maximum load which needs to be overcome by the actuator at a predefined minimum speed for a given hydraulic pressure range. "Actuator effort" is the maximum theoretical force which a hydraulic servo actuator is able to provide. There is the difference between these two terms i.e. Actuator effort and Stall load. This difference is because of various friction forces caused by used hydraulic seals. In general, stall load is the difference of actuator effort and seals friction force which an actuator can drive under specific pressure conditions. It is necessary to estimate the actuator effort to drive the maximum stall load after considering the effect of seal friction, effect of hydraulic pressure tolerances and effect of dimensional tolerances. Thus, the very first step during preliminary design phase should be the calculation of actuator effort after consideration of pressure tolerances, dimensional tolerances and effect of seals friction, which must be more than the specified stall load. If estimated actuator effort is less than the stall load requirements then this difference will be the main reason for not meeting the minimum speed requirement during testing phase.

This paper explains all these useful design parameters through a real case study example where for a given customer requirements, actuator effort was estimated after considering the effects of pressure tolerances and dimensional tolerances. The theoretical estimation of friction force caused by all seals was estimated and found useful in calculating the accurate actuator effort. Later on, validation of these estimated values was successfully carried out on an actual development prototype.

\section{PRELIMINARY SIZING TO MEET THE REQUIREMENTS}

The case study servo hydraulic actuator is powered with dual redundant hydraulic systems with an operating pressure of 3000 psi. In order to meet the envelope size, a tandem piston arrangement was selected for the case study servo hydraulic actuator. Typically, two options are available for design of any aircraft servo hydraulic actuator in the case of dual hydraulic systems. This is mainly decided by the arrangement of pistons that includes a parallel actuator configuration or tandem actuator configuration with one isolated cylinder for each hydraulic system. In a parallel actuator configuration, two pistons are arranged in parallel and mechanically connected to each other at one end and then integrated with the aircraft structure. This configuration is preferable where limited space is available in actuator lengthwise direction. This architecture is in use for many hydraulic actuators of both fixed wing and rotary wing aircraft like Sikorsky S-76 main rotor actuator . In a tandem actuator configuration, pistons with two heads are connected in tandem and so this type of actuator is longer but with smaller cylinder diameter as double the piston area is available to drive the same load compared to a parallel actuator. This type of arrangement is very popular where enough space is available in the lengthwise direction. This architecture is also in use on many aircraft like Bell 212 main rotor actuator. ${ }^{1}$

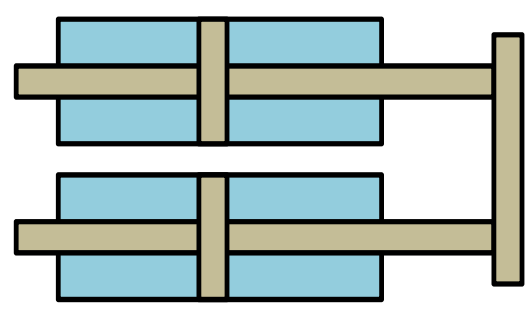

Figure 1: Parallel Actuator Configuration

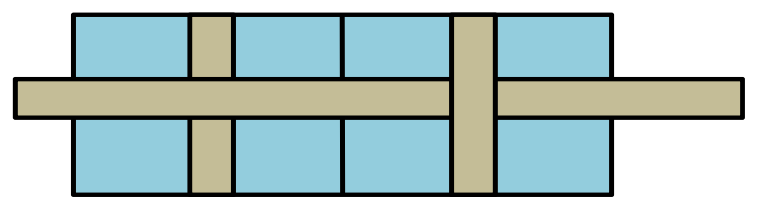

Figure 2: Tandem Actuator Configuration

The prime factor behind the selection of a particular arrangement is the space availability. Parallel actuator design results in shorter length but wider assembly size, whereas tandem actuator design leads to longer length but with smaller cross-section.

The relevant design parameters as extracted from internal technical specification are summarized in Table 1. 
Table 1

Basic Design Parameters

\begin{tabular}{ll}
\hline Parameter & Value \\
\hline Nominal Supply Pressure & $206 \pm 4$ bars \\
Nominal Return Pressure & $5 \pm 1$ bars \\
Double Cylinder Stall Load & 55640 Newton (N) \\
\hline
\end{tabular}

The tolerance on hydraulic pressure plays an important role during performance and environmental testing, as it is not possible to keep constant pressure during the whole period on the test stand. Environmental test standard "MIL-STD$810 \mathrm{~F}$ " also specifies a tolerance of $\pm 5 \%$ of value on hydraulic pressure. ${ }^{2}$ The above given stall load is for a double cylinder arrangement and so to calculate the effective area, single cylinder stall load of half of double cylinder stall load is used $(27820 \mathrm{~N})$. The working pressure at the actuator port is the difference between the supply pressure and return pressure. Initially, tolerances on pressure were not considered and so the working pressure was taken as 201 bars.

Therefore, Effective area; $=$ Single cylinder stall load/ working pressure $=1384 \mathrm{~mm}^{2}$

Effective area $=\pi / 4 \times\left(D_{c}{ }^{2}-d_{r}{ }^{2}\right)$

It is preferable and good design practice to keep the ratio of cylinder full area to rod end area equal to or less than 2 . This is to avoid the large difference between extended and retracted speeds. Hence,

Cylinder full area/ rod end area $\leq 2$

$\left[\pi / 4 \times\left(\mathrm{D}_{\mathrm{c}}{ }^{2}-\mathrm{d}_{\mathrm{r}}{ }^{2}\right)\right] /\left[\pi / 4 \times \mathrm{d}_{\mathrm{r}}{ }^{2}\right] \leq 2$

It gives $D_{c} / d_{r} \leq 1.732$ or $d_{r} \geq 0.577 \times D_{c}$

Based on above relationship, $\mathrm{d}_{\mathrm{r}}=0.6 \times \mathrm{D}_{\mathrm{c}}$

Therefore, Cylinder ID $\left(\mathrm{D}_{\mathrm{c}}\right)=52.49 \mathrm{~mm}$

Piston $\operatorname{rod} \mathrm{OD}\left(\mathrm{d}_{\mathrm{r}}\right)=31.49 \mathrm{~mm}$

The nearest standard dimensions were selected as per MILG-5514 standard ${ }^{3}$ and seal dash number 218 was found suitable for gland (inner seal) and seal dash number 225 was found suitable for the piston head (outer seal). The relevant dimensions as per MIL-G-5514 are summarized in Table 2 and shown in Figure 2 for clarity with typical groove details.

Table 2

\section{Seal Installation Dimensions}

\begin{tabular}{lcl}
\hline $\begin{array}{l}\text { Seal Installation } \\
\text { Dimensions }\end{array}$ & $\begin{array}{l}\text { Extreme Limits } \\
(\mathrm{mm})\end{array}$ & $\begin{array}{l}\text { Mean Value } \\
(\mathrm{mm})\end{array}$ \\
\hline Rod Groove Seal Dash Number 218: & \\
Rod OD $\left(\mathrm{d}_{\mathrm{r}}\right)$ & $31.69 / 31.64$ & 31.67 \\
Gland ID $\left(\mathrm{D}_{\mathrm{g}}\right)$ & $31.75 / 31.77$ & 31.76 \\
Gland groove ID $\left(\mathrm{D}_{\mathrm{gr}}\right)$ & $37.87 / 37.92$ & 37.89 \\
Piston Groove Seal Dash Number 225: & \\
Cylinder ID $\left(\mathrm{D}_{\mathrm{c}}\right)$ & $53.79 / 53.84$ & 53.82 \\
Piston OD $\left(\mathrm{d}_{\mathrm{p}}\right)$ & $53.72 / 53.69$ & 53.70 \\
Piston groove OD $\left(\mathrm{d}_{\mathrm{gp}}\right)$ & $47.62 / 47.57$ & 47.59 \\
\hline
\end{tabular}

The actual effective area was cross checked again with the above selected dimensions for driving the designated stall load.

$$
\begin{aligned}
& \text { Therefore, Effective area }=\pi / 4\left(53.82^{2}-31.67^{2}\right) \\
& =1486.53 \mathrm{~mm}^{2}
\end{aligned}
$$

This effective area is more than $1384 \mathrm{~mm}^{2}$ as calculated earlier. It means actuator is fully able to drive the stall load.

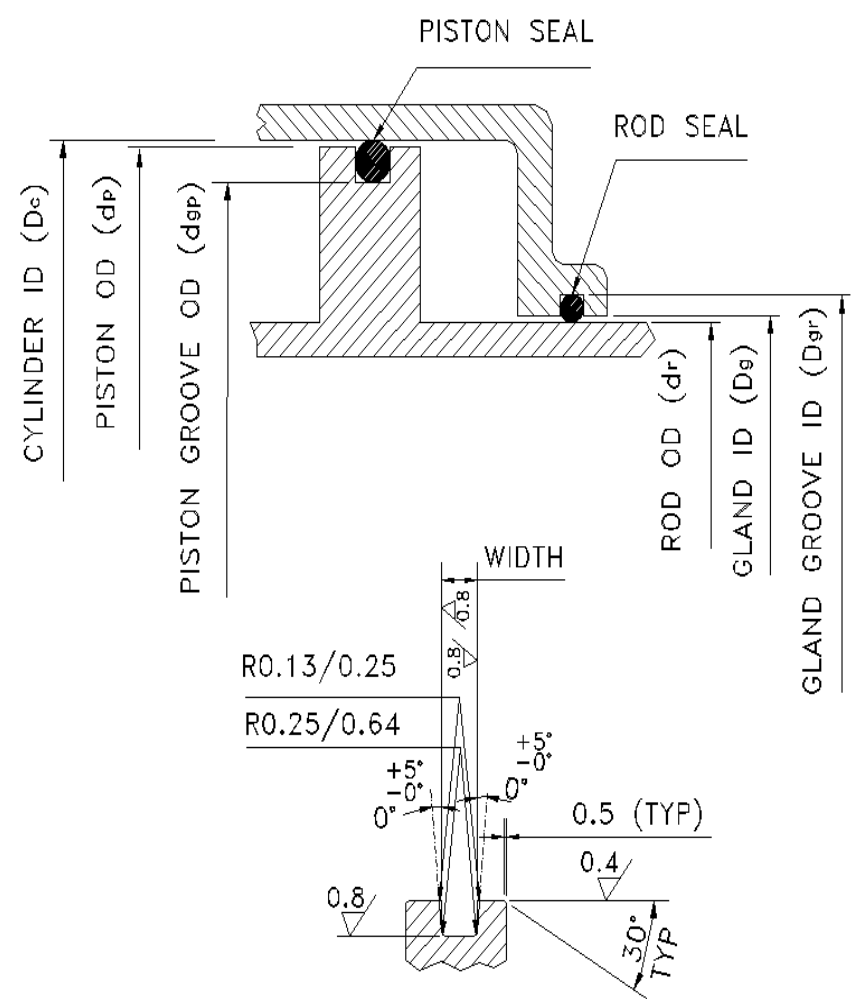

Figure 3: Installation Dimensions with Groove Details

\section{THEORETICAL ESTIMATION OF ACTUATOR EFFORT}

Based on the above pressure and dimensional tolerances as given in Table 1 and Table 2, actuator effort values were calculated by multiplying the effective pressure and piston annular area for various single cylinder and double cylinder cases. The actuator effort values as obtained by the above exercise are summarized in Table 3.

Table 3

Estimated Actuator Effort Results

\begin{tabular}{ll}
\hline Case & Actuator Effort (N) \\
\hline Single Cylinder (Min) & 29136 \\
Single Cylinder (Max) & 30622 \\
Double Cylinder (Min) & 58272 \\
Double Cylinder (Max) & 61244 \\
\hline
\end{tabular}

It can be visualized easily from Table 3 , that the estimated minimum actuator effort is more than the stall load 
requirement for both single cylinder and double cylinder cases. However, in addition to drive the stall load, the actuator also needs to overcome the seals friction which has significant influence on actuator characteristics. Therefore, it is necessary to estimate the seals friction and include its effect on stall load.

\section{THEORETICAL ESTIMATION OF SEAL FRICTION FORCE}

The initial force needed to overcome seal friction is known as breakout force, and this friction is known as breakout friction. In dynamic applications, there is a difference between running and breakout friction. Breakout friction must be overcome at the starting and therefore it is also called start-up friction. During this stage, adhesive forces between the seal and metal interface have to be overcome and so a high start up force is required. Running friction or dynamic friction is when the seal is in motion having already passed the breakout stage. After establishment of movement, these forces come down to a lower value known as running friction. As a guide to the order of magnitude, breakout friction is normally expected to be twice that of the running friction. ${ }^{4}$ Apart from other physical parameters pertaining to the seal; coefficient of friction is required to calculate the seal friction. This friction coefficient is dependent on a number of factors like sliding materials, surface finish, seal design, seal material, movement speed, pressure, condition of lubrication, temperature, and length of time remaining in physical contact at rest. ${ }^{5}$ These factors are making the mathematical analysis very complicated and not possible to make the exact statements for level of friction which can be expected during operation. These factors are related to seals, hydraulic fluid and working conditions as given below: ${ }^{6}$

Factors related to Sealing Element:

- Hardness and surface finish

- Swelling and temperature characteristics

- Geometrical and dimensional tolerances

- Dry and lubricated compound friction values

Factors related to Hydraulic Fluid:

- Viscosity and temperature relationship

- Chances to build up a lubrication film and its distribution pattern

Factors related to Working conditions:

- Operating hydraulic pressure

- Movement speed

- Load applied

- Material and surface finish of related components

- Radial clearances for seal installation

These factors are difficult to quantify as they act and overlap cumulatively. However, the general effect of these factors for a lower value of seal friction is summarized in Table 4.
Table 4

Effects of Various Factors on Seal Friction ${ }^{6}$

\begin{tabular}{ll}
\hline Factor & $\begin{array}{l}\text { Affect on } \\
\text { Friction }\end{array}$ \\
\hline Seal squeeze & Reduce \\
Metal surface finish & Reduce \\
Rubber hardness & Reduce \\
Movement speed & Increase \\
Seal cross-section & Reduce \\
Hydraulic pressure & Reduce \\
Temperature & Increase \\
Groove width & Increase \\
Rod or bore diameter & Reduce \\
Time for remaining in physical contact at rest & Reduce \\
\hline
\end{tabular}

\section{Mathematical Relationship Used}

The seal friction force value used during the preliminary design phase is an approximation since accurate friction values for every seal are difficult to measure and depends on a number of parameters, as explained above. A commonly accepted method of predicting seal friction incorporates the use of curves that includes friction due to seal squeeze and due to hydraulic pressure. The friction value of an ' $O$ ' ring is given by equation (1). ${ }^{7}$

$$
\mathrm{F}=\left(\mathrm{F}_{\mathrm{C}}+\mathrm{F}_{\mathrm{H}}\right)=\left(\mathrm{f}_{\mathrm{c}} \times \mathrm{L}+\mathrm{f}_{\mathrm{h}} \times \mathrm{A}\right)
$$

The descriptions of various parameters used in equation (1) are given in Table 5.

Table 5

Seal Friction Calculation Parameters

\begin{tabular}{|c|c|c|}
\hline \multicolumn{2}{|c|}{ Parameters } & \multirow{2}{*}{$\begin{array}{l}\text { Description } \\
\text { Total friction force due to } \\
\text { seal squeeze }\end{array}$} \\
\hline $\mathrm{F}_{\mathrm{C}}$ & $f_{c} \times L$ & \\
\hline $\mathrm{F}_{\mathrm{H}}$ & $\mathrm{f}_{\mathrm{h}} \times \mathrm{A}$ & $\begin{array}{l}\text { Total friction force due to } \\
\text { fluid pressure }\end{array}$ \\
\hline$f_{c}$ & As given in Figure 4 & $\begin{array}{l}\text { Friction (lb per inch seal } \\
\text { contact length) }\end{array}$ \\
\hline $\mathrm{f}_{\mathrm{h}}$ & As given in Figure 5 & $\begin{array}{l}\text { Friction (lb per inch }{ }^{2} \text { seal } \\
\text { projected area) }\end{array}$ \\
\hline $\mathrm{L}$ & & Circumference: \\
\hline \multirow{5}{*}{ A } & $\pi \times D_{\mathrm{gr}}$ & For rod groove seal \\
\hline & $\pi \times D_{c}$ & For piston groove seal \\
\hline & & Seal projected area: \\
\hline & $\pi / 4 \times\left(D_{g r}^{2}-d_{r}^{2}\right)$ & For rod groove seal \\
\hline & $\pi / 4 \times\left(D_{c}^{2}-d_{g p}^{2}\right)$ & For piston groove seal \\
\hline
\end{tabular}

The friction per inch length $\left(f_{c}\right)$ due to seal compression/squeeze is taken up from Figure 4 and friction per square inch of seal projected area $\left(f_{h}\right)$ due to fluid pressure is taken up from Figure 5. 


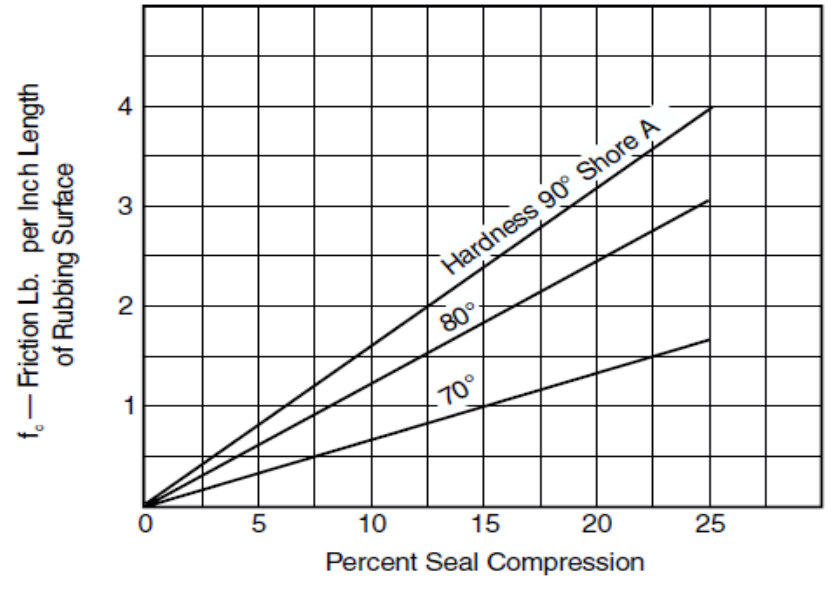

Figure 4: Friction due to Seal Squeeze ${ }^{7}$

The importance of initial squeeze in the O-ring groove is essential to ensure its function as a primary or secondary sealing element. Initial squeeze will serve to achieve the initial sealing capability and to assure the defined frictional forces. In dynamic applications, the maximum recommended squeeze is approximately $16 \%$, due to friction and wear considerations, though smaller cross-sections may be squeezed as much as $25 \%$. When used as a static seal, the maximum recommended squeeze for most elastomers is $30 \%$, although this amount may cause assembly problems in a radial squeeze seal design. ${ }^{8}$ Sealing performance can also be shown by the amount of squeeze, because the increased amount of squeeze above the established limits can cause a high friction and excessively high actuating forces, whereas the low-squeeze below the limits means lowering the sealing pressure and so increasing the leakage tendency. Standards like MIL-G-5514, AS4716 ${ }^{9}$ and other special catalogs are usually used to provide the O-ring dimensions and the recommended range of squeeze value, also the working tolerances and the groove specifications.

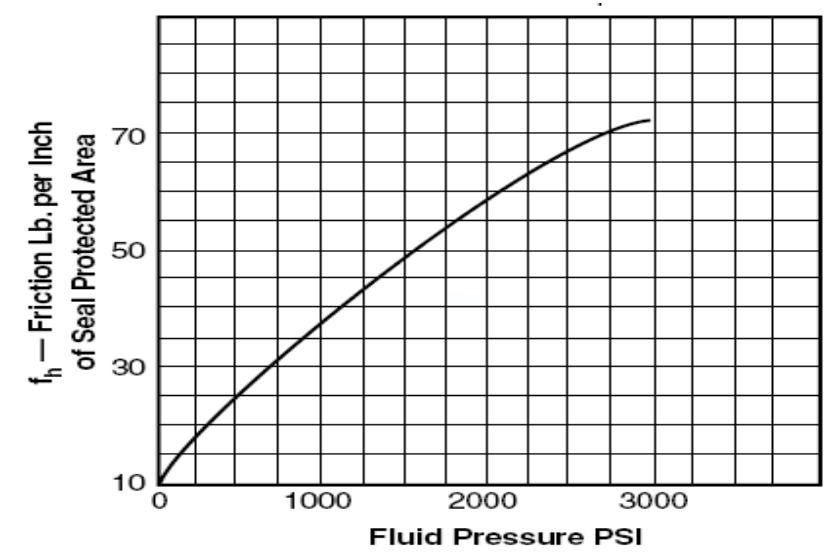

Figure 5: Friction due to Hydraulic Fluid Pressure ${ }^{7}$

\section{Piston Groove Seal}

The friction calculation for piston groove seal was carried out by using above methodology and shown in Table 6 .
Table 6

Calculation of Piston Groove Seal Friction

\begin{tabular}{|c|c|}
\hline \multicolumn{2}{|c|}{$\begin{array}{l}\text { Hardness }=75 \text { Shore A for rubber compound } \\
\text { Percentage compression for seal of dash no- } 225=8.5 \text { to } 15 \\
\% \text { as per MIL-G- } 5514 \text {. }\end{array}$} \\
\hline $\begin{array}{l}\text { Maximum } \mathrm{f}_{\mathrm{c}}=1.4 \mathrm{lb} \text { per } \\
\text { inch }\end{array}$ & $\begin{array}{l}\text { For compression of } 15 \% \text { and } \\
\text { hardness of } 75 \text { Shore A from } \\
\text { Figure } 4 .\end{array}$ \\
\hline $\mathrm{L}=6.65 \mathrm{inch}$ & $\mathrm{L}(\max )=\pi \times \mathrm{D}_{\mathrm{c}}$ \\
\hline$f_{h}=73 \mathrm{lb}$ per inch ${ }^{2}$ & $\begin{array}{l}\text { For } 3000 \text { psi system pressure } \\
\text { from Figure } 5 \text {. }\end{array}$ \\
\hline $\mathrm{A}=0.77 \mathrm{inch}^{2}$ & Area $(\max )=\pi / 4\left(\mathrm{D}_{\mathrm{c}}{ }^{2}-\mathrm{d}_{\mathrm{gp}}{ }^{2}\right)$ \\
\hline \multicolumn{2}{|c|}{$\mathrm{F}=(1.4 \times 6.65)+(73 \times 0.77)=65.38 \mathrm{lb}=290.83 \mathrm{~N}$} \\
\hline
\end{tabular}

\section{Rod Groove Seal}

Friction for rod groove seal was also calculated based on same methodology and given in Table 7.

Table 7

\section{Calculation of Rod Groove Seal Friction}

\begin{tabular}{|c|c|}
\hline \multicolumn{2}{|c|}{$\begin{array}{l}\text { Hardness }=75 \text { Shore } A \text { for rubber compound } \\
\text { Percentage compression for seal of dash no- } 218=8.5 \text { to } 15 \\
\% \text { as per MIL-G-5514. }\end{array}$} \\
\hline $\begin{array}{l}\text { Maximum } \mathrm{f}_{\mathrm{c}}=1.4 \mathrm{lb} \text { per } \\
\text { inch }\end{array}$ & $\begin{array}{l}\text { For compression of } 15 \% \text { and } \\
\text { hardness of } 75 \text { Shore A from } \\
\text { Figure } 4 .\end{array}$ \\
\hline $\mathrm{L}=4.68$ inch & $\mathrm{L}(\max )=\pi \times \mathrm{D}_{\mathrm{gr}}$ \\
\hline$f_{h}=73 \mathrm{lb}$ per inch ${ }^{2}$ & $\begin{array}{l}\text { For } 3000 \text { psi system pressure } \\
\text { from Figure } 5 \text {. }\end{array}$ \\
\hline $\mathrm{A}=0.53$ inch $^{2}$ & Area $(\max )=\pi / 4\left(\mathrm{D}_{\mathrm{gr}}^{2}-\mathrm{d}_{\mathrm{r}}^{2}\right)$ \\
\hline \multicolumn{2}{|c|}{$\mathrm{F}=(1.4 \times 4.68)+(73 \times 0.53)=45.02 \mathrm{lb}=200.25 \mathrm{~N}$} \\
\hline
\end{tabular}

The above friction values are for one each type of seal. The total numbers of seals are required to estimate the full seal friction force which needs to be overcome by the actuator. In order to provide close chamber architecture to tandem-piston arrangement, there are two cylinders as connected together. There is one piston head in each of cylinder to facilitate the extension and retraction of the ram which means, there are in total two piston groove seals, one on each piston head. The cylinder needs to be covered on both sides with glands to prevent leakage and so there are two glands per cylinder. The piston rod is moving under glands bore and in order to provide effective leakage control, it is always better to provide two dynamic seals on each gland. This results in total eight rod groove seals. 


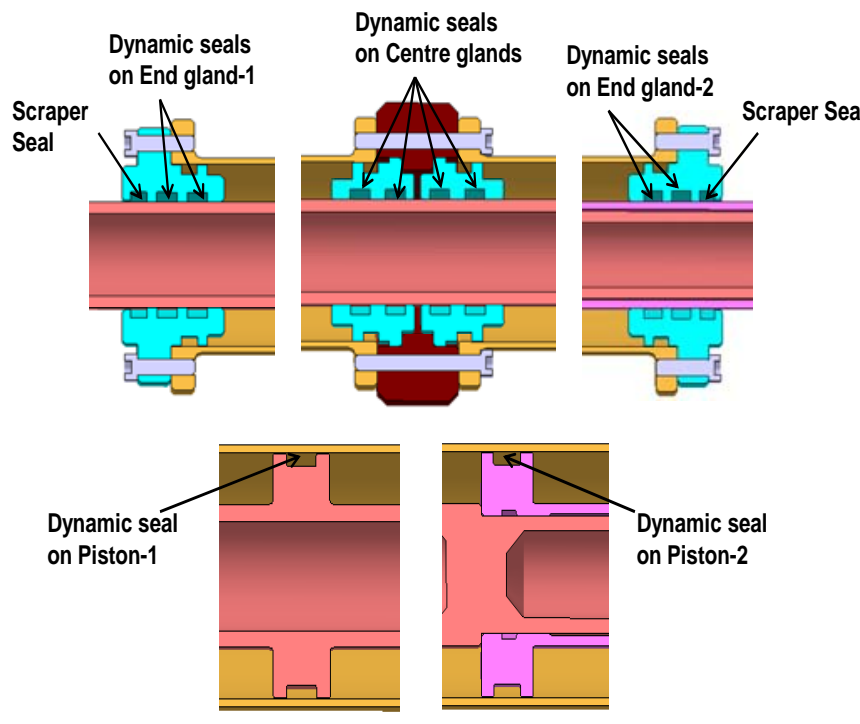

Figure 6: Location of Dynamic Seals in Power Actuator

Hence, a total of eight dynamic rod seals and two dynamic piston seals are used in the power actuator design to prevent internal and external leakage and provide the effective hydraulic force with the arrangement shown in Figure 6 . Therefore, theoretically estimated total seal friction developed by all these seals would be $2184 \mathrm{~N}$.

The above method for calculating seal friction is suitable for ' $\mathrm{O}$ ' rings only and not appropriate to consider for low friction Ener-caps as selected in this application. In the actual prototype units, Ener-cap type dynamic seals were selected from Green Tweed Company (GTC) to suit the dash number 225 for piston groove and 218 for rod groove to meet the requirements. These Ener-caps are self-actuating and pressure activated hydraulic seals that optimize seal performance. These seals offer low breakout and running friction with very low leakage for longer working life. The part number of the piston groove Ener-cap is 52-6-225-00964-019-0 and rod groove Ener-cap is 52-3-218-00-964019-0. In addition, Scraper seals are also used to prevent entry of dust/ foreign contaminants at both end glands. The selected Ener-cap type dynamic seals and scraper seal for this application are shown in Figure 7.
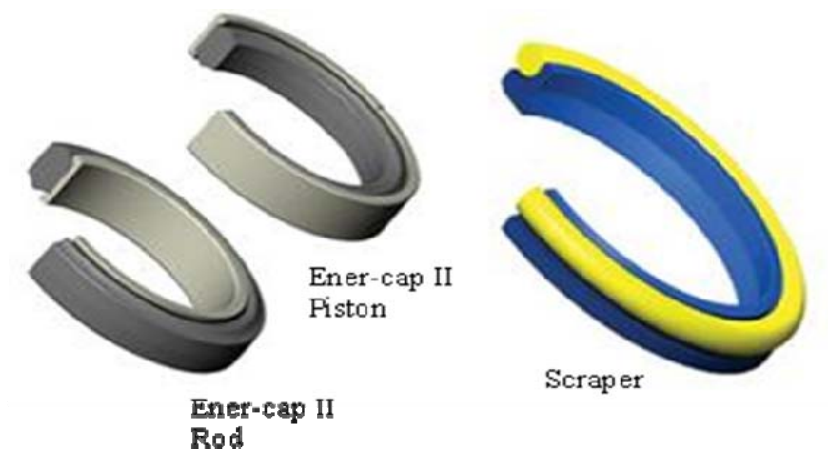

Figure 7: Ener-Cap II series and 2270 series Scraper ${ }^{10,11}$
The friction value for these types of seals (Ener-caps) is to be reduced by about 50 to 60 percent to that of ' $\mathrm{O}$ ' rings because of advanced materials and technology. Here, it is assumed that Ener-cap seal friction is reduced only by $50 \%$ of same size of ' $\mathrm{O}$ ' ring. Therefore, total seal friction for Ener-cap type seals:

$$
=50 \% \text { of ' } \mathrm{O} \text { ' rings friction }=1092 \mathrm{~N}
$$

\section{VALIDATION OF THEORETICALLY ESTIMATED SEAL FRICTION}

As already mentioned, this theoretical estimation of seal friction force is an approximation during design phase. It is necessary to validate this seal friction force using a development prototype to get actual and more accurate results. This section is focusing on the methodology adopted to measure the actual seal friction force for the case study hydraulic servo actuator.

\section{Methodology Adopted}

There are two methods for measurement and validation of seal friction force as given below:

- By measuring the external force required to move the piston of an unpressurized hydraulic actuator.

- By measuring the pressure at which piston of hydraulic actuator just starts to move and then this pressure has to be multiplied by the effective annular area to get the friction force.

Both methods were used to measure seal friction force for different conditions of actuator in the present application. The eight possible conditions were followed to measure and record the friction force as given in Table 8. Friction force was measured using a Force Gauge in cases 1 and 2 whereas by recording the hydraulic pressure in cases 3 to 8 .

Table 8

Various Conditions to Measure Seal Friction Force

\begin{tabular}{|c|c|c|c|}
\hline Case & Condition & Cylinder-1 & Cylinder-2 \\
\hline 1 & Retraction & Both Ports open & Both Ports open \\
\hline 2 & Extension & Both Ports open & Both Ports open \\
\hline 3 & Retraction & $\begin{array}{l}\text { Pressure to port } 1 \\
\& \text { port } 2 \text { open }\end{array}$ & $\begin{array}{l}\text { Both ports } 3 \& 4 \\
\text { open }\end{array}$ \\
\hline 4 & Extension & $\begin{array}{l}\text { Pressure to port } 2 \\
\& \text { port } 1 \text { open }\end{array}$ & $\begin{array}{l}\text { Both ports } 3 \& 4 \\
\text { open }\end{array}$ \\
\hline 5 & Retraction & $\begin{array}{l}\text { Both ports } 1 \& 2 \\
\text { open }\end{array}$ & $\begin{array}{l}\text { Pressure to port } \\
3 \& \text { port } 4 \text { open }\end{array}$ \\
\hline 6 & Extension & $\begin{array}{l}\text { Both ports } 1 \& 2 \\
\text { open }\end{array}$ & $\begin{array}{l}\text { Pressure to port } \\
4 \& \text { port } 3 \text { open }\end{array}$ \\
\hline 7 & Retraction & $\begin{array}{l}\text { Pressure to port } 1 \\
\& \text { port } 2 \text { open }\end{array}$ & $\begin{array}{l}\text { Pressure to port } \\
3 \& \text { port } 4 \text { open }\end{array}$ \\
\hline 8 & Extension & $\begin{array}{l}\text { Pressure to port } 2 \\
\& \text { port } 1 \text { open }\end{array}$ & $\begin{array}{l}\text { Pressure to port } \\
4 \& \text { port } 3 \text { open }\end{array}$ \\
\hline
\end{tabular}




\section{Experimental Test Set-Up}

The prototype unit was mounted on a fixture plate with the help of five bolts as shown in Figures 8 and 9 below.

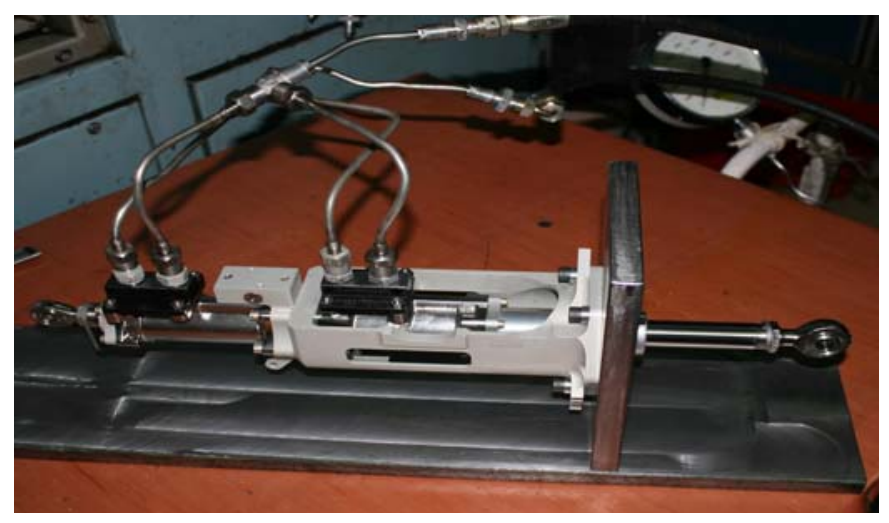

Figure 8: Prototype Unit on Test Stand in Extended Position

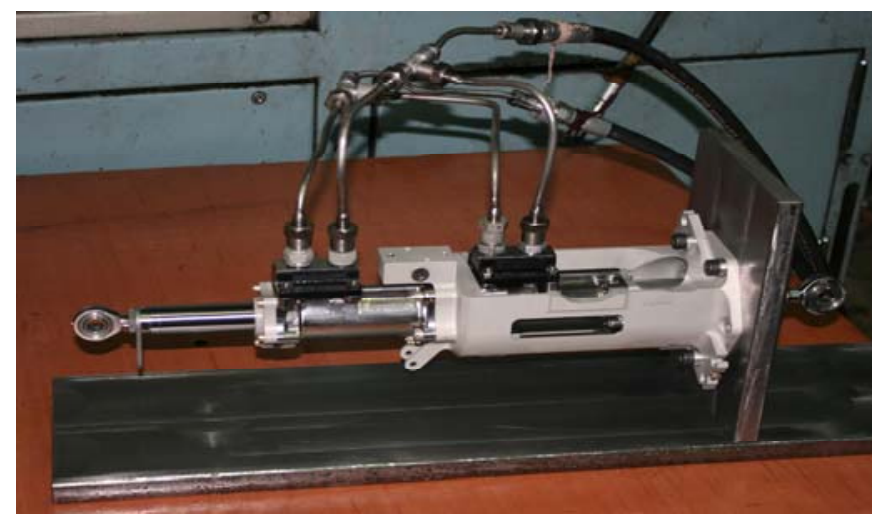

Figure 9: Prototype Unit on Test Stand in Retracted Position

Figure 8 shows the extended position of the actuator ram whereas Figure 9 is showing the retracted position of the actuator ram. After mounting the prototype unit, the following steps were followed.

Step 1: Make hydraulic connections to the prototype unit using a hand pump as per Figure 10 and Figure 11.

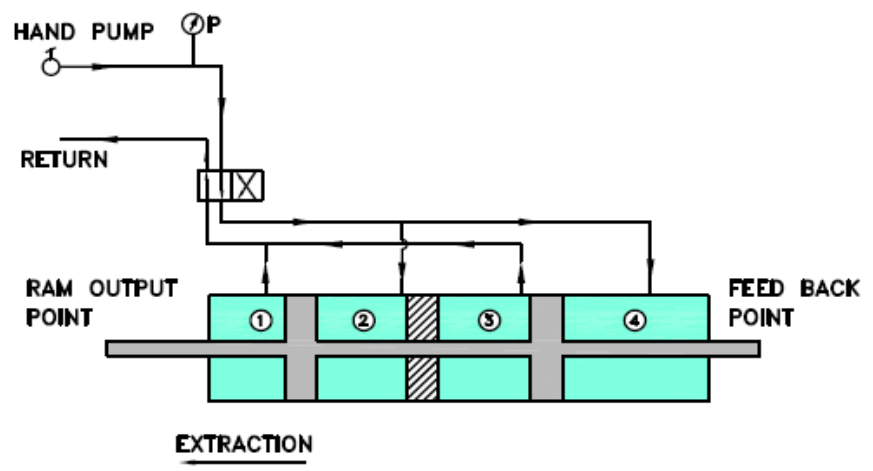

Figure 10: Hydraulic Connection Details for Extension

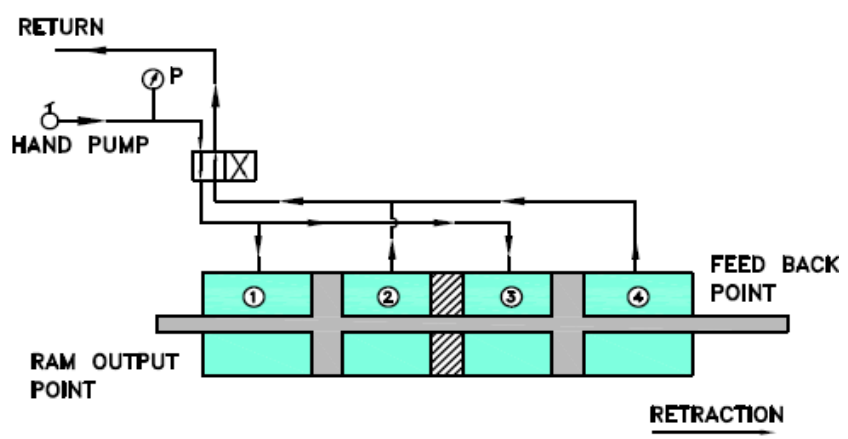

Figure 11: Hydraulic Connection Details for Retraction

Step 2: Gradually increase the hydraulic pressure simultaneously in Chambers $2 \& 4$ as shown in Figure 10; just enough to extend the piston and bring the piston to fully extended position.

Step 3: Gradually increase the hydraulic pressure simultaneously in chambers $1 \& 3$ as shown in Figure 11; just enough to retract the piston and bring the piston to fully retracted position.

Step 4: Repeat steps $2 \& 3$ to complete five cycles of actuation to confirm its smooth operation and to spill oil all over internally.

Step 5: Testing carried out based on different eight cases as mentioned above and test results were recorded accordingly.

\section{Seal Friction Force Test Results}

In first two cases (Case-1 \& Case-2), maximum force recorded on the force gauge during retraction/extension is the total seal friction force. Whereas, in the remaining six cases (From Case-3 to Case-8), the maximum pressure recorded during retraction/extension was multiplied by the effective area to get the total seal friction force. The force and pressure were recorded in all of the above cases accordingly. The effective area is $1486 \mathrm{~mm}^{2}$ based on cylinder bore diameter and piston rod diameter. Table 9 summarizes the test results.

Table 9

Seal Friction Force Test Results

\begin{tabular}{lll}
\hline Test condition & $\begin{array}{l}\text { Recorded } \\
\text { Pressure (psi) }\end{array}$ & $\begin{array}{l}\text { Seal Friction } \\
\text { Force (N) }\end{array}$ \\
\hline Case-1 & N/A & 1045 \\
Case-2 & N/A & 1035 \\
Case-3 & 96 & 984 \\
Case-4 & 101 & 1034 \\
Case-5 & 97 & 994 \\
Case-6 & 99 & 1014 \\
Case-7 & 49 & 1004 \\
Case-8 & 50 & 1024 \\
\hline
\end{tabular}




\section{CORRELATION BETWEEN THEORETICALLY ESTIMATED \& ACTUAL TESTED RESULTS}

The theoretically estimated seal friction force is $1092 \mathrm{~N}$ whereas average tested seal friction force on actual prototype unit is $1017 \mathrm{~N}$. It can be visualized clearly here that theoretically estimated seal friction force is very much in line with practically tested average seal friction force. The difference between these two results is less than $10 \%$ which is fully acceptable during both preliminary and detailed design phases by all stakeholders. The minor difference in results may be due to many factors that were considered during above analysis like seal design, certain assumptions and working conditions involving temperature and surface finish. However, the major reason behind this difference in results may be due to the assumption of $50 \%$ of seal friction force for low friction Ener-cap type seals to that of the same size of ' $\mathrm{O}$ ' rings.

Accordingly, stall load values were revised in the Technical Specification after subtracting $1100 \mathrm{~N}$ as maximum seal friction force from actuator effort values. The same is summarized in Table 10.

Table 10

Revised Stall Load after Considering Seal Friction

\begin{tabular}{llll}
\hline $\begin{array}{l}\text { Stall Load } \\
\text { Case }\end{array}$ & $\begin{array}{l}\text { Actuator } \\
\text { Effort (N) }\end{array}$ & $\begin{array}{l}\text { Average } \\
\text { Seal } \\
\text { Friction (N) }\end{array}$ & $\begin{array}{l}\text { Revised } \\
\text { Stall } \\
\text { Load (N) }\end{array}$ \\
\hline $\begin{array}{l}\text { Single Cylinder } \\
\text { (Min) }\end{array}$ & 29136 & 1100 & 28036 \\
$\begin{array}{l}\text { Single Cylinder } \\
\text { (Max) }\end{array}$ & 30622 & 1100 & 29522 \\
$\begin{array}{l}\text { Double } \\
\text { Cylinder (Min) }\end{array}$ & 58272 & 1100 & 57172 \\
$\begin{array}{l}\text { Double } \\
\text { Cylinder (Max) }\end{array}$ & 61244 & 1100 & 60144 \\
\hline
\end{tabular}

\section{CONCLUSIONS}

The comparison between the theoretically estimated results and actual obtained test results shows that the computed results through using the developed mathematical relationship were in a good agreement with those experimentally obtained. This shows the validity of using this formula for determining the seal friction force during the early design stage before the prototype is built. Experimentally and theoretically, the relationship was confirmed within the acceptable working limits. Using this method, one can avoid any changes in hardware at a later date which otherwise proved to be very time consuming and cost overrun exercise.

These stall load values are obtained not only after consideration of seal friction but also after taking into account the practical limits, i.e. pressure tolerances and dimensional tolerances; which otherwise are un-avoidable during testing of the unit and manufacturing of its components. This study also shows the importance of seal friction to stall load capability and the value of considering this important aspect from the beginning.

\section{REFERENCES}

1. Woodward. Main and Tail Hydraulic Actuators, http://www.woodward.com/RotorFlightControls.aspx (2015, accessed 11 November 2015).

2. MIL-STD-810F:2000. Test Method Standard for Environmental Engineering Considerations and Laboratory Tests.

3. MIL-G-5514 G: 1993. General Requirements for Hydraulic Gland Design and Packings.

4. Rana A.S. and Sayles R.S. An Experimental Study on the Friction Behaviour of Aircraft Hydraulic Actuator Elastomeric Reciprocating Seals. Tribology and Interface Engineering Series 2005; 48:507-515.

5. Ruff A. W. Typical Friction and Wear. In: Booser E. R. (editor) Tribology Data Handbook: An Excellent Friction, Lubrication and Wear Resource. Florida: CRC Press, 1997, pp. 435-444.

6. ' $\mathrm{Parker}$ ' Ring Handbook, http://www.deltamotion.com/peter/Hydraulics/Valves /Parker/Seal_Friction_Parker_Seals.pdf (2015, accessed $20 \overline{\text { October }} \overline{2015) \text {. }}$

7. Warring R. H. Seals and Sealing Handbook. 1st ed. London: Trade \& Technical Press Ltd, 1981.

8. Al-Ghathian F. and Tarawneh M.S. Friction Forces in O-ring Sealing. American Journal of Applied Sciences 2005; 2(3): 626-632.

9. SAE AS 4716B:2011. Gland Design, O-Ring and Other Elastomeric Seals.

10. Green Tweed. Ener-Cap II - High Performance Bidirectional Seal, http://www.gtweed.com/markets/aerospace/applicatio ns/flight-control-systems/ designs/cap-seals-ener-capii-ener-cap-ii-hp/ (2015, accessed 15 September 2015).

11. Green Tweed. 2270 Series Scraper-Double Acting PTFE Scraper, http://www.gtweed.com/markets/aerospace/products/ sealing-systems/designs/scrapers-2270-series/ (2015, accessed 15 September 2015). 
2016-05-10

\section{A practical method to account for seal friction in aircraft hydraulic actuator preliminary design}

Agarwal, Naresh K.

SAGE

Agarwal NK, Lawson CP, A practical method to account for seal friction in aircraft hydraulic actuator preliminary design, Proceedings of the Institution of Mechanical Engineers, Part G:

Journal of Aerospace Engineering, Vol. 231, Iss. 5, pp. 941-950

http://dx.doi.org/10.1177/0954410016645371

Downloaded from Cranfield Library Services E-Repository 